\title{
Growth of Candida species in liquid culture medium for Trichomonas vaginalis
}

\author{
Y J ERDMAN, J M HOLTON, AND A BECKER \\ From the Department of Microbiology, Middlesex Hospital Medical School, London
}

SUMMARY The growth of Candida spp from vaginal specimens in Bushby's liquid medium for $T$ vaginalis was compared with that on Sabouraud's agar medium, and isolation was significantly greater in Bushby's medium ( $\mathrm{p}<0.001)$. Isolations missed $(4.43 \%)$ in Bushby's medium probably represented vaginal carriage of small numbers of Candida spp.

\section{Introduction}

Feinberg and Whittington observed that Candida spp grew well in culture medium for Trichomonas vaginalis. ${ }^{1}$ Both these organisms cause vaginal disease, ${ }^{23}$ and it would be cost effective if they could be isolated from a single liquid medium. To compare the isolation rate of Candida spp on conventional Sabouraud's agar with that obtained in modified Feinberg-Whittington medium ${ }^{4}$ a prospective study was carried out in the department of genitoruinary medicine at this hospital.

\section{Patients and methods}

\section{DESIGN STUDY}

All women patients (1029) who attended during a six week period in March and April 1982 were included. A loopful of material was taken from the lateral vaginal wall, Gram stained, and examined for Candida spp. Three specimens were taken for culture from each patient using a nichrome wire loop. A sample from the cervical os was inoculated into Bushby's modified Feinberg-Whittington medium. ${ }^{4}$ Two samples were taken from the lateral vaginal wall and inoculated either into Bushby's medium or onto Sabouraud's agar (Oxoid) and incubated at $37^{\circ} \mathrm{C}$ for two days. In the first three week period Bushby's medium was inoculated first, but the order of inoculation was reversed in the second period.

IDENTIFICATION OF CANDIDA SPP

Identification of Candida spp by their typical colonial appearance on Sabouraud's agar was confirmed by microscopical examination for budding

Address for reprints: Mr Y J Erdman, Department of Microbiology, Middlesex Hospital Medical School, London W1P 7LD

Accepted for publication 13 June 1983 yeast cells. In Bushby's medium microscopical examination revealed budding yeast cells and pseudomycelium. Selected isolates of Candida spp were tested by Analytical Profile Index (API) to identify the species. These isolates were also tested for germ tube production..$^{5}$ A random selection of 207 isolates of Candida spp was surveyed for germ tube production to determine what proportion were Candida albicans.

\section{GROWTH KINETICS OF C ALBICANS IN}

BUSHBY'S MEDIUM

An isolate of $C$ albicans was emulsified in $0.85 \%$ saline (about $3.0 \times 10^{6}$ colony forming units $(\mathrm{cfu}) / \mathrm{ml}$ ) and $1 \mathrm{ml}$ of a range of dilutions was inoculated into $9 \mathrm{ml}$ aliquots of Bushby's medium. The growth curves were plotted by means of a nephelometer to determine the rate of increase in optical density. Viable counts were performed on the dilutions by standard microbiological techniques.

The growth kinetics in Bushby's medium of seven strains that had grown only on Sabouraud's agar on primary isolation was compared with that of three others that grew in both media. About $5 \times 10^{3} \mathrm{cfu}$ were inoculated into Bushby's medium and the optical density measured by nephelometry.

\section{Results}

\section{ISOLATION OF CANDIDA SPECIES}

The table shows that Candida spp were isolated from $226(22.0 \%)$ of the 1029 patients in either or both media. In the first three week period isolation of Candida spp in Bushby's medium was significantly $(p<0.001)$ greater than on Sabouraud's agar, whereas there was no significant difference in yields from the two media in the second period when Sabouraud's agar was inoculated first. Over the 
TABLE Growth of Candida spp from 1029 women

\begin{tabular}{|c|c|c|c|}
\hline \multirow[b]{2}{*}{ Medium } & \multicolumn{3}{|c|}{ No of specimens yielding candidal growth } \\
\hline & In weeks $1-3 *$ & In weeks 4-6† & In total period \\
\hline $\begin{array}{l}\text { Sabouraud's only } \\
\text { Bushby's only } \\
\text { Both } \\
\text { Neither }\end{array}$ & $\begin{array}{r}4 \\
23 \\
101 \\
429\end{array}$ & $\begin{array}{r}6 \\
13 \\
79 \\
374\end{array}$ & $\begin{array}{r}10 \\
36 \\
180 \\
803\end{array}$ \\
\hline Total & 557 & 472 & 1029 \\
\hline
\end{tabular}

*Bushby's medium inoculated before Sabouraud's agar;

t Sabouraud's agar inoculated before Bushby's medium.

entire period, however, the isolation was significantly $(p<0.001)$ greater in Bushby's medium. Samples from 10 women, however, failed to grow Candida spp in Bushby's medium although growing on Sabouraud's agar, which is equivalent to $4 \cdot 4 \%$ false negative results $(95 \%$ confidence limits of $p$ are $1 \cdot 7 \%$ and $7 \cdot 1 \%$ ).

Of the 207 isolates of Candida spp taken at random, $195(94 \cdot 2 \%)$ were identified as Candida albicans by a positive germ tube test.

\section{INOCULUM SIZES}

Fig 1 shows the growth curves obtained by inoculation of varying numbers of $C$ albicans into Bushby's medium. As few as $300 \mathrm{cfu} / \mathrm{ml}$ gave rise to appreciable growth within 24 hours, and even an inoculum as small as $1-5 \mathrm{cfu} / \mathrm{ml}$ would establish growth by the fifth day.

\section{GROWTH KINETICS OF VARIOUS ISOLATES \\ OF C ALBICANS}

Isolates that grew only on Sabouraud's agar on primary isolation were all identified as $C$ albicans. Fig 2 shows the growth kinetics of seven such strains compared with that of three others that grew on both media. The latter showed a faster growth rate in the first 18 hours and a slightly greater growth at 28 hours.

\section{Discussion}

The significantly greater isolation of Candida spp from Bushby's medium than from Sabouraud's agar would imply that a liquid medium like the former would suffice for both Candida spp and $T$ vaginalis. In a small percentage of patients, however, primary isolation was only from Sabouraud's agar. The reasons for this are not entirely clear, but these patients were probably harbouring very small numbers of Candida spp, which represented vaginal carriage as opposed to infection. Failure to grow in Bushby's medium may therefore be attributed to chance, particularly as examination of the case notes

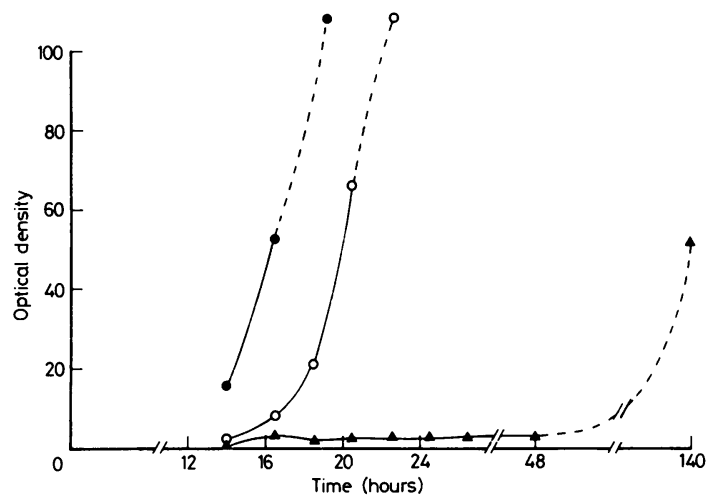

FIG 1 Growth curves of three inoculum sizes of a strain of $C$ albicans in Bushby's medium $(O=$ Inoculum about $3 \times 10^{4} \mathrm{cfu} / \mathrm{ml} ; \mathrm{O}=$ Inoculum about $3 \times 10^{2}$ $\mathrm{cfu} / \mathrm{ml} ; \boldsymbol{\Lambda}=$ Inoculum about $1-5 \mathrm{cfu} / \mathrm{ml}$; ...... = extrapolations).

of the 10 women concerned showed that they had no clear cut signs or symptoms of candidosis. Moreover, a Gram stained smear of material (taken from the lateral vaginal wall before the specimens for culture) gave negative results for Candida spp in these cases. The order in which the media were inoculated played a major role in their respective isolation rates, as can be judged by comparison of the data from the first and second time periods (see table). Not surprisingly, this indicated that the major part of the material went to the first medium inoculated.

The percentage of the 207 isolates of Candida spp identified as $C$ albicans $(\mathbf{9 4} \cdot \mathbf{2 \%})$ was similar to that reported by Hurley et $a l^{6}$ and Oriel et al. ${ }^{7}$

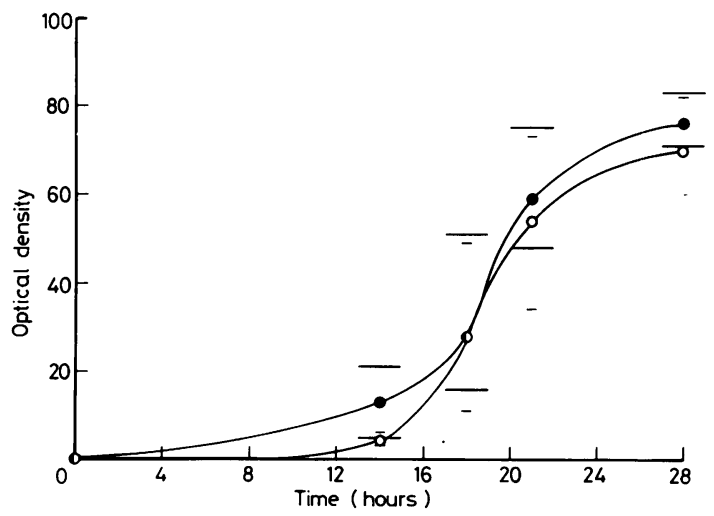

FIG 2 Growth of C albicans in Bushby's medium from a standard inoculum. A comparison of isolations that grew only on Sabouraud's agar with those that grew on both media on primary isolation $\mathrm{O}=C$ albicans from Sabouraud's agar only (range of seven experiments $==1 ; 0=C$ albicans from both media (range of three experiments $=$ =). 
Growth curve experiments showed that an inoculum of less than $100 \mathrm{cfu} / \mathrm{ml}$ of Calbicans would give rise to appreciable growth within 48 hours. All 10 isolates that failed to grow in Bushby's medium were identified as $C$ albicans, but they may have been a biotype that did not grow well in this medium. A comparison of the growth characteristics of seven of these strains with three that had been isolated from both media (see Fig 2) showed that the growth yield after 28 hours was not noticeably reduced. Of note, however, was that the seven strains which grew only on Sabouraud's agar had a longer lag phase, but that once they entered the log phase the mean generation time was reduced.

No attempt was made in this study to determine the minimum inoculum of Candida spp required to establish growth on Sabouraud's agar, so that a direct comparison in this respect with Bushby's medium is not possible.

When both Candida spp and $T$ vaginalis are present in the same tube of Bushby's medium, $T$ vaginalis may be overgrown with the Candida spp by the second day of incubation ( $Y \mathrm{~J}$ Erdman, unpublished observation). Extra care should therefore be taken in microscopial examination of tubes that contain Candida spp.
We thank Dr R D Catterall and the staff of the department of genitourinary medicine at the Middlesex Hospital for their help, Ms E M Belsey for statistical analysis, and Mrs D R Colthorpe and Mrs J Joshi for technical help.

\section{References}

1. Feinberg JG, Whittington MJ. A culture medium for Trichomonas vaginalis Donné and species of Candida. J Clin Pathol 1957; 10:327-9.

2. Carroll CJ, Hurley $\mathbf{R}$, Stanley VC. Criteria for diagnosis of Candida vulvovaginitis in pregnant women. Journal of Obstetrics and Gynaecology of the British Commonwealth 1973;80:258-63.

3. Catterall RD, Nicol CS. Is trichomonal infestation a venereal disease? Br Med J 1960; i: $1177-9$.

4. Bushby SRM, Copp FC. The antitrichomonal activity of amidonitrothiazoles. J Pharm Pharmacol 1955; 7:112-7.

5. Taschdjian CL, Burchall JJ, Kozinn PJ. Rapid identification of Candida albicans by filamentation on serum and serum substitutes. Am J Dis Child 1960;99:212-5.

6. Hurley R, Leask BGS, Faktor JA, de Fonseka CI. Incidence and distribution of yeast species and of Trichomonas vaginalis in the vagina of pregnant women. Journal of Obstetrics and Gynaecology of the British Commonwealth 1973;80:252-7.

7. Oriel JD, Partridge BM, Denny MJ, Coleman JC. Genital yeast infections. Br Med $J$ 1972; iv: 761-4. 